\title{
APPLICATION OF GEOPHYSICAL METHODS TO THE STUDY OF THE MECHANISM OF SPRINGS
}

\author{
Vargemezis G. ${ }^{1}$, Tsourlos $\mathbf{P}^{1}{ }^{1}$, and Stamoulis $\mathbf{K}^{2}$ \\ 'Department of Geophysics, Aristotle's University of Thessaloniki, GREECE, varge@geo.auth.gr, \\ Tsourlos@geo.auth.gr \\ ${ }^{2}$ Power Public Corporation S.A
}

\begin{abstract}
The application of geophysical investigation to the study of the mechanism of a spring system is discussed. The springs are located within the Southern mine field of the Power Public Corporation in Ptolemais (Greece) in a small valley which is supposed to be filled with the excavation products of the mine. Thus, the aim is to protect the stability of the future valley fill from the water circulation at its floor.

The scope of the survey is to study the mechanism of the spring in order to pump the underground water and minimize the water supply of the main source.

A number of wells have been constructed along a line that was considered to cross the path of the underground water in order to pump the water but they failed. Geophysical investigation has been decided in order to contribute to the solution of the problem. Electrical tomographies have been conducted in an effort to detect the underground path where the underground water flows towards the springs.

The results of the application of geoelectrical tomography and VLF methods showed a faulting system where the underground water is flowing and finally forms the springs.
\end{abstract}

Key words: Tomography, VLF, spring.

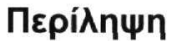

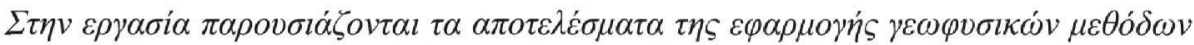

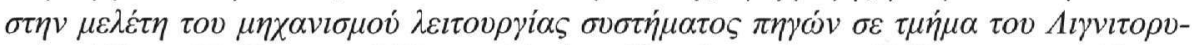

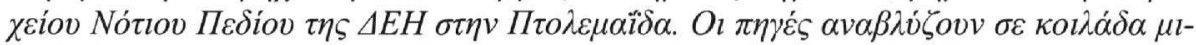

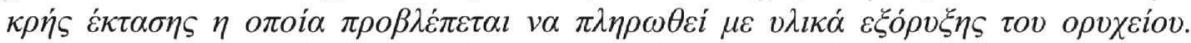

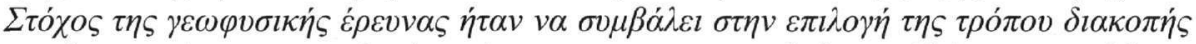

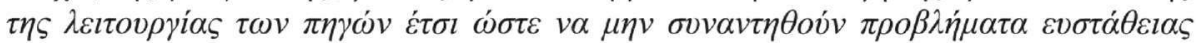

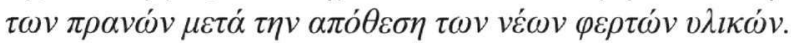

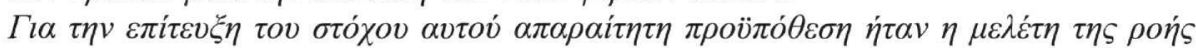

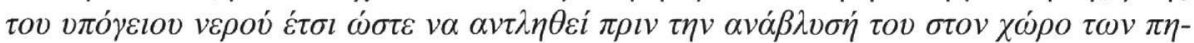

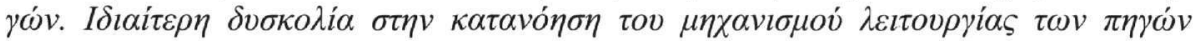

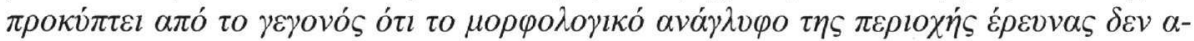

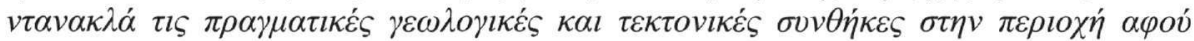

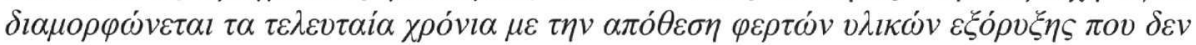

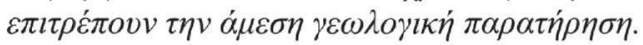




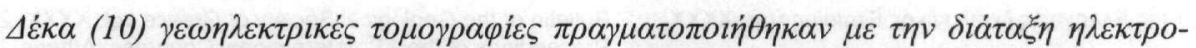

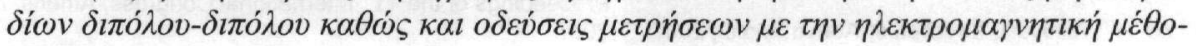

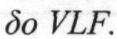

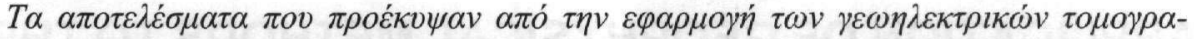

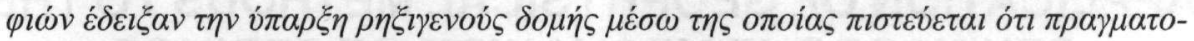

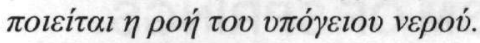

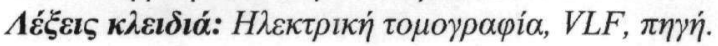

\section{Introduction}

Valley fills are carefully engineered earth and rock structures designed and constructed to safely and permanently hold excess rock and other native material generated from excavation activities such as mining.

Coal industry officials all over the world are concerned about the creation of natural drainage in valley fills that keeps them from retaining water. If water builds up in a valley fill, it affects the fill's stability the same way that too much water in the ground can cause mudslides and other landslips.

In the valley that is planned to be filled two springs exist providing approximately $60 \mathrm{~m}^{3} / \mathrm{h}$ of water. The water is filling a small artificial lake. These springs cause a serious problem for the construction of the valley fill since the flow of the water is expected to draw away the filling materials and thus cause problems on the stability of the valley fill.

A number of wells that have been constructed along a line that was thought to cross the underground channels of the water missed to find them.

Geophysical methods are widely used to the hydrogeological study. In particular, geophysical methods have been proved to be effective to the study of stability problems i.e. landslides etc (Friedel et al. 2006, Roth et al. 2002, Sultan et al. 2004, among others).

The methods of electrical tomography and VLF electromagnetic have been applied. Profiles in various directions around the springs as well as close to the wells have been measured. The wells have been used mainly as calibration data since the geological columns were known.

\section{General information of the area surveyed}

\subsection{Location-Topography}

The area is located between the villages Pteleon and Charavgi (Fig. 1) $13 \mathrm{~km}$ SouthEast of the Prolemais city.

The relief of the area in Figure 2 is the initial relief and it does not reflect the present situation since valley fills have changed the original topography. That poses difficulties since it makes more difficult the recognition of geological formations and structures in the field.

\subsection{Geological setting of the area.}

The geological map of the area has been reconstructed from the IGME map on the scale of 1:50000 (Fig. 2).

The geological formations that are mapped in the area surveyed are:

Recent alluvial deposits and elluvial formations: (Al): Sands, gravel and clay.

Brecciated slide rocks $\left(\boldsymbol{P t}_{l-c s}\right)$ : Formation of old breccia which is containing red clays and limestone particles. 


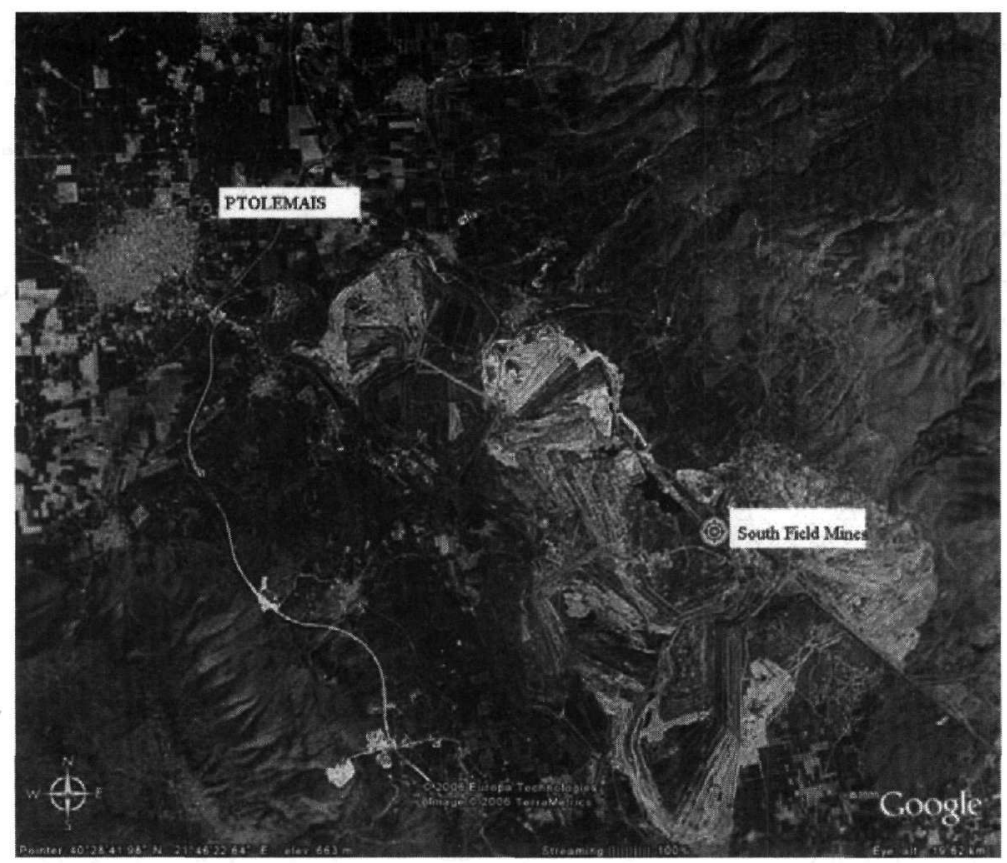

Figure 1 - Location of the area surveyed (South Field Mines)

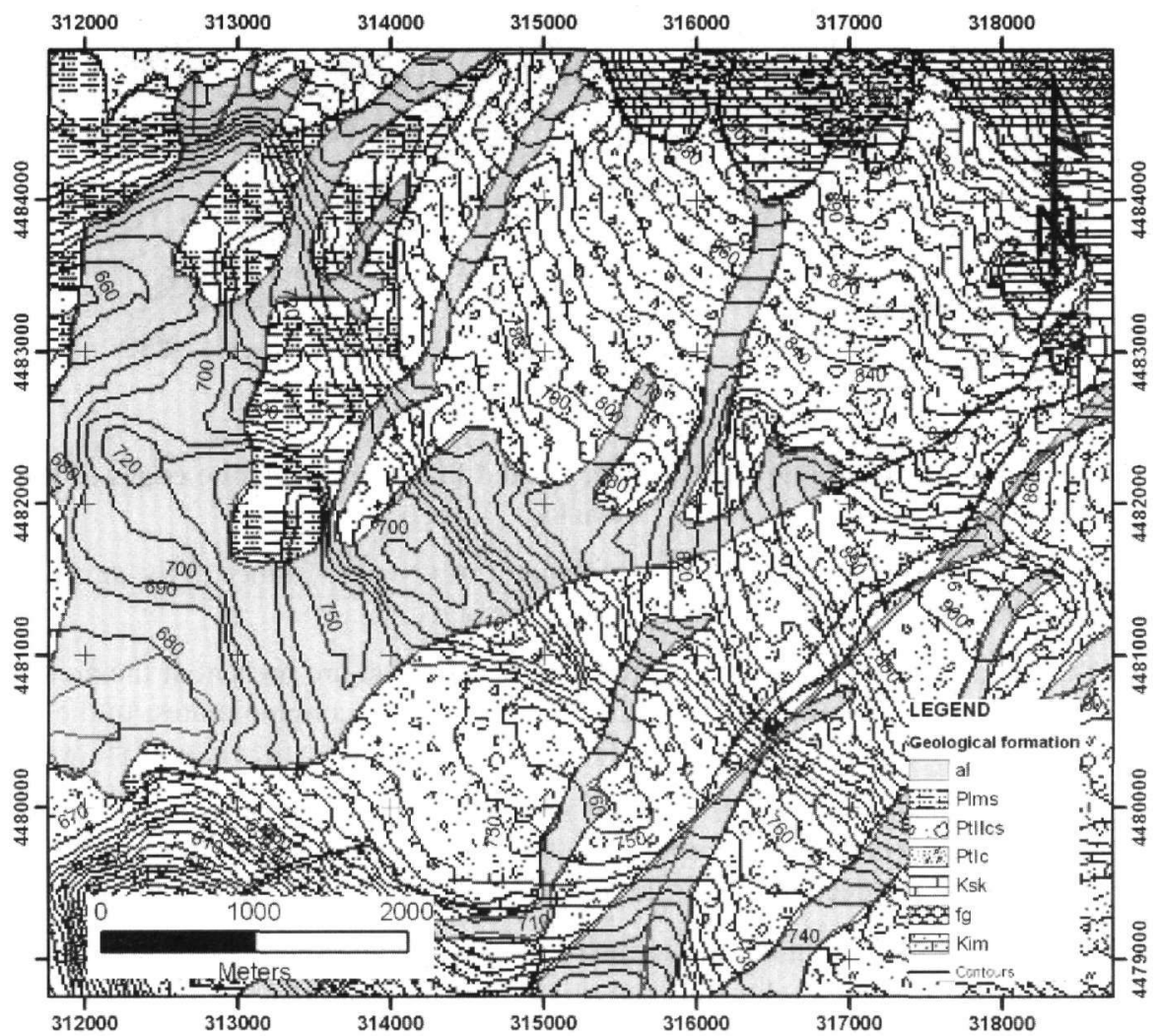

Figure 2 - Geological map of the area 
In detail, geology close to the area consists from three particular layers (from the top):

Upper layer: Alternation of white marls and thin beds of marly limestones.

Middle layer: Finely granular and biochemical sediments (clay, white marl and thin layers of lignite).

Lower layer: Conglomerates, red clays that turn to sand and marls to the top.

Detailed information about the near surface geology of the area arises from the wells that have been constructed at the area in order to pump the underground water.

A group of springs is present in the area (Fig. 3).

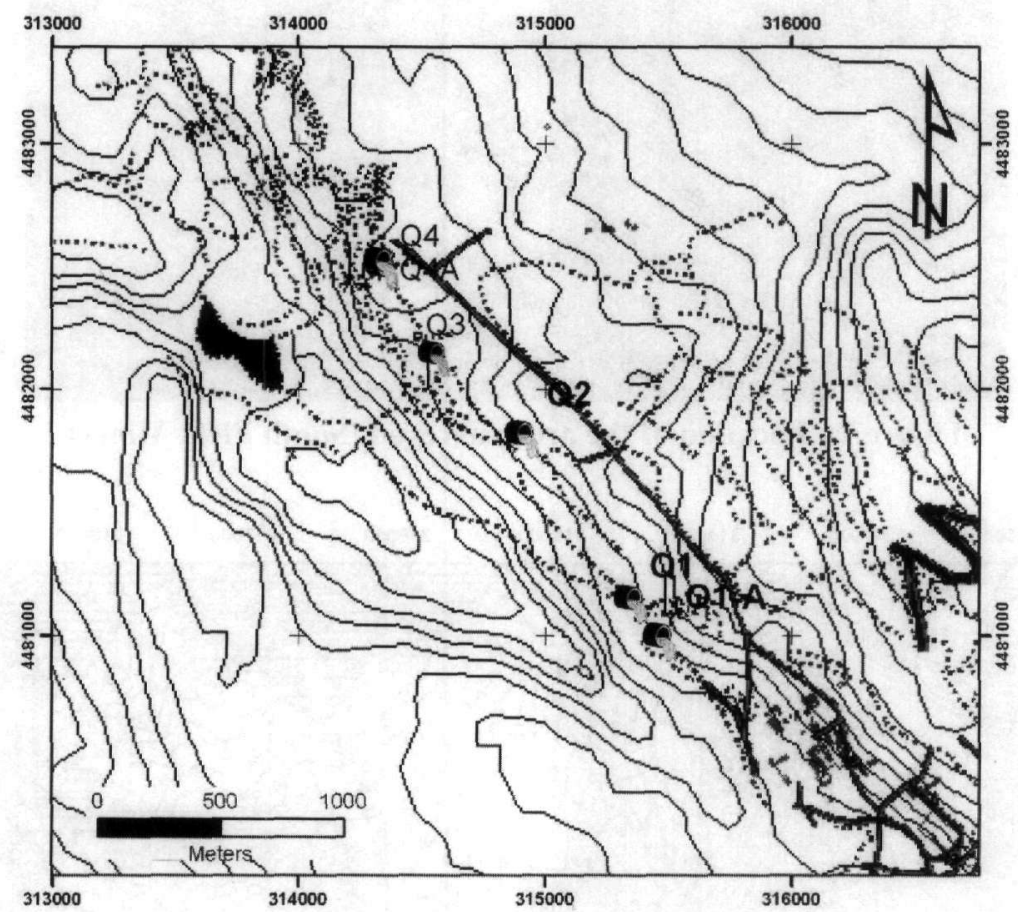

Figure 3 - Location of the springs (Q1-2-3-4). Dotted lines represent the edges of the earthworks

The most interesting springs are the Q1 $\left(40 \mathrm{~m}^{3} / \mathrm{h}\right)$ and Q1A $\left(20 \mathrm{~m}^{3} / \mathrm{h}\right)$, since in the small valley that is close to the springs a valley fill is planned to be constructed.

The study of the hydrogeological behavior of the formations that are present at the area show that underground water could flow either to the marly limestone or to conglomerates. In the case of the limestone secondary permeability in faulted areas is assumed to allow the flow of the water.

In the geological columns of the wells that are mapped on the right, three geological units are present. The upper one (dark color) represents the red-brown clay, in the middle the marly limestone is formed and the deeper layer is the formation of marl, clay and lignite.

The water level is observed within the formation of the marly limestone. The problem is, that, even the wells are all drilled in a line to the northeastern part of the springs the water supply in the best case is less than $6 \mathrm{~m}^{3} / \mathrm{h}$. . That notice does not agree with the initial interpretation of the water flow to the springs from the northeast direction. 

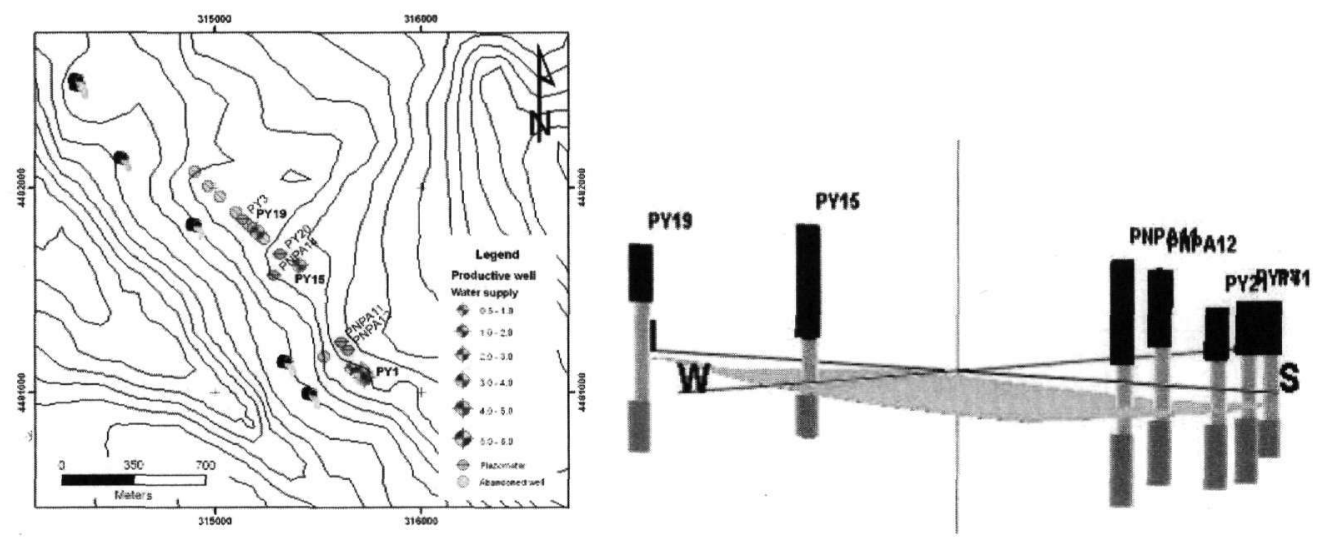

Figure 4 - Wells constructed at the area (on the left). Geological columns and water level (on the right)

Thus, geophysical survey has been decided in order to provide more detailed information about the geological and tectonic structure of the area in relation to the underground water flow.

\section{Methods applied}

\subsection{Electrical tomography}

The parameters of the tomography have been adapted to the geological setting of the area. The electrode array of dipole-dipole has been selected.

The SYSCAL instrument has been used for the electrical tomography.

Since the maximum depth of investigation was set to 80 meters the parameters were:

- Electrode separation (a): 3-5 m

- Maximum distance between current electrode and potential dipole was set to $n * a, n * 2 a$ and $n * 3 a$ where maximum value of $n$ was 8 .

The expected depth of the array described with these parameters is close to 95 meters and in the initial tomography 690 measurements of the apparent resistivity have been measured (Fig. 5).

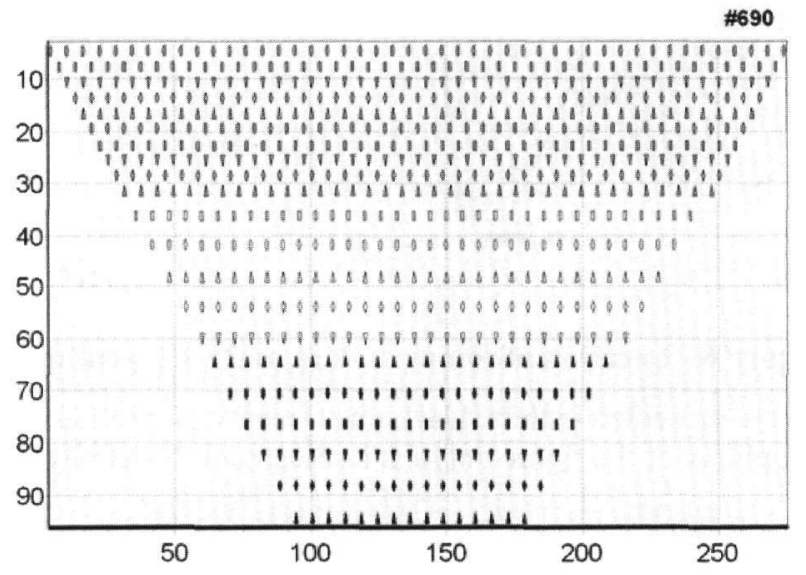

Figure 5 - Sketch of the designed tomography 
The Tsourlos (1995) algorithm for the inversion of the data has been used in addition with the RES2DINV program (Li and Oldenburg 1992).

Topography has been taken under consideration in order to get the realistic resistivity distribution in the area.

\subsection{VLF electromagnetic method.}

The WADI (ABEM Instruments) instrument has been used in order to measure the tilt angle and ellipticity of the magnetic component of the electromagnetic field.

VLF method is widely used for the detection of conductive zones that reflect the existence of faulting structures filled with material as clay or water.

Secondary electromagnetic field produced by a primary one propagating in conductive zones is measured and enable us to detect the source.

Raw data which refer to the real (tilt) and imaginary (ellipticity) component of the magnetic field are processed further in order to be interpreted. Fraser filter has been applied in the first place while Karous-Hjelt filter has also been applied.

Sector software (ABEM Instruments) as well as the Nissen's (1986) programs have been used.

The first one permits the qualitative interpretation of the data since Nissen's code allows the characterization of the faulting zones as concern their resistivity. Thus, more accurate interpretation as concern the material that fills the faults is achieved.

\section{Field survey-Interpretation}

As it is mentioned before, electrical tomography and VLF measurements have been conducted. The location of measured profiles is presented in Fig. 6.
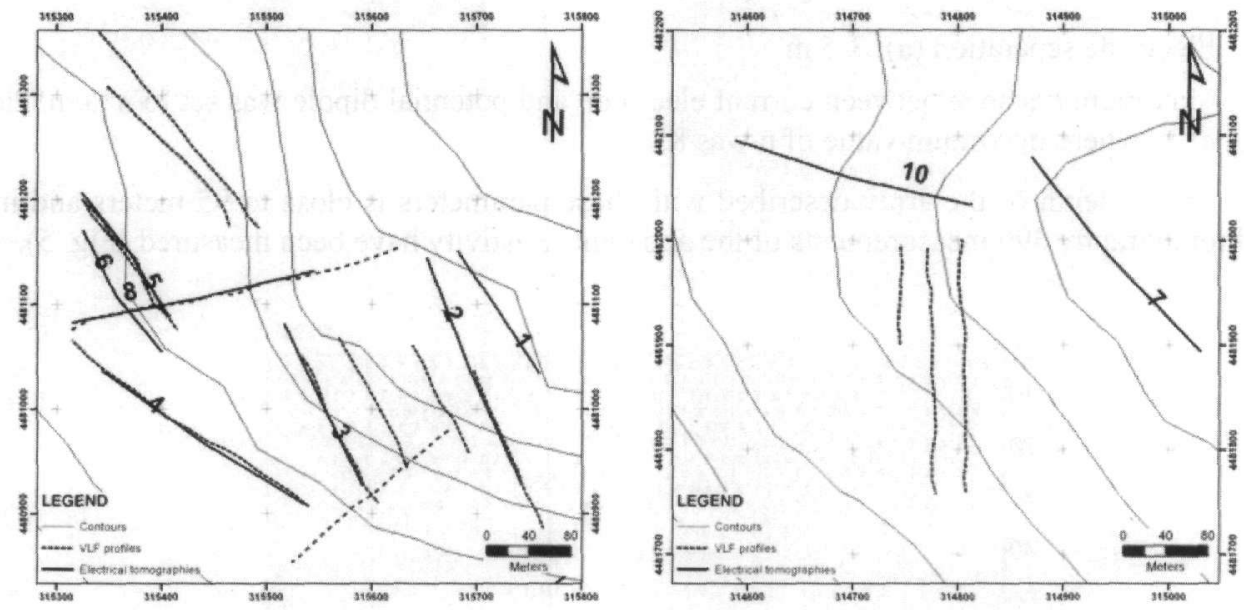

Figure 6 - Location of tomographies and VLF profiles

Electrical tomographies are presented in thick black lines since VLF profiles are presented with dashed lines. For the simplicity of the figure only ERT (Electrical Resistivity Tomography) are numbered.

The concept of arranging the profiles was to detect fracture systems at the direction of North-East / South West and North-West / South-East respectively. 


\subsection{Electrical tomography}

Ten (10) electrical tomographies have been conducted in a total length of 2000 meters. Electrode separation was $3 \mathrm{~m}$. for ERT 1,5 and 6 and $5 \mathrm{~m}$. for the rest.

For the shake of space economy only representative inversion results are presented. Raw data, inversion model and final resistivity model of the tomographies are presented in Figures 7 and 9.

The tomography is represented in three parts. In the upper part the raw data are drawn. In the middle one, the initial inversion model is represented and at the bottom, the final resistivity model is shown.
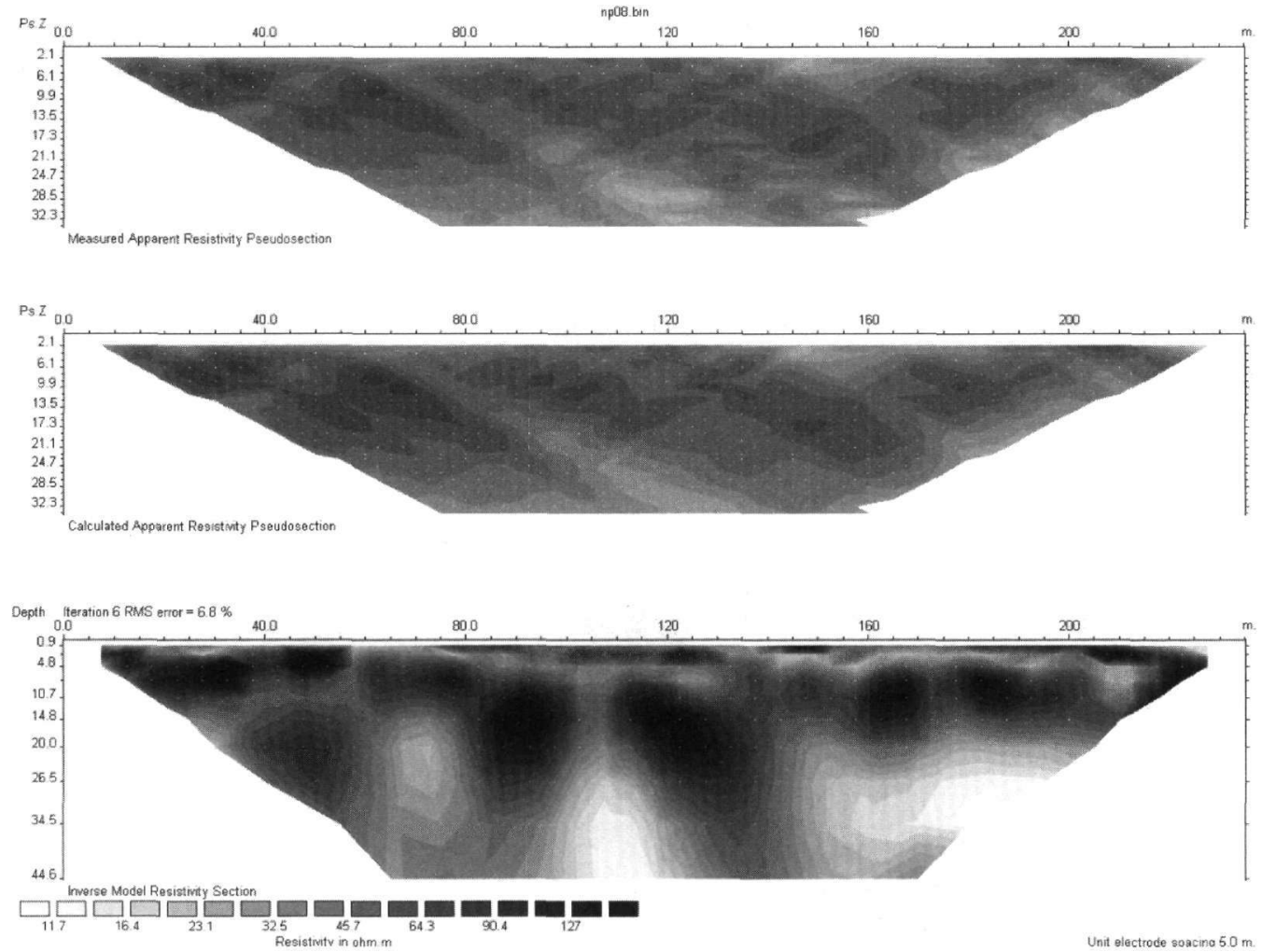

Figure 7 - Tomography NP8

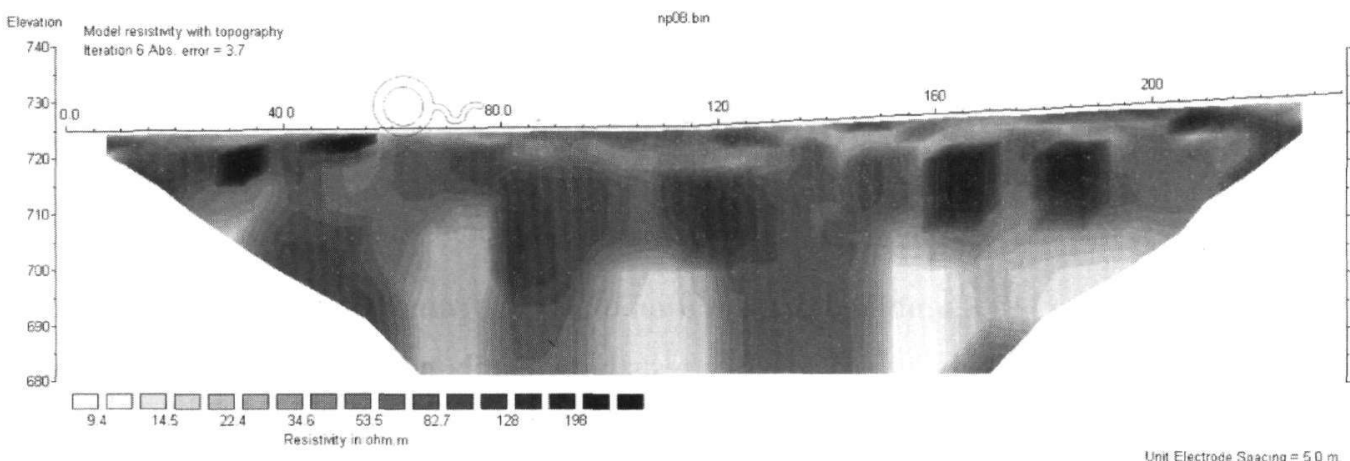

Figure 8 - Robust inversion in addition to topography correction of ERT NP8 


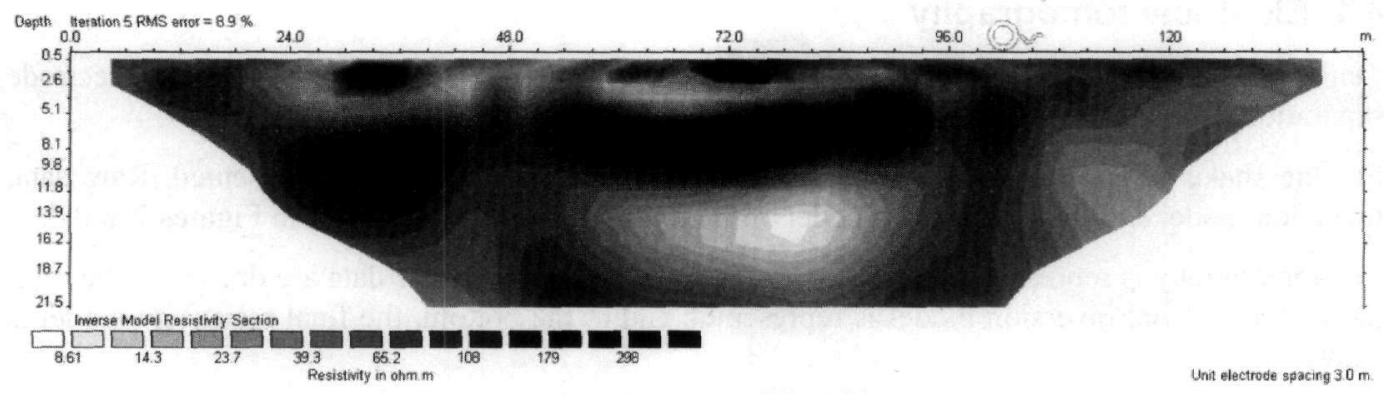

Figure 9 - Electrical resistivity tomography NP6

Since the elevation had a significant increase towards the north-eastern part of the tomography, topography correction has been estimated while Robust inversion has been applied in order to enhanced the lateral sensitivity of the inversion. The final result is shown in Figure 9.

We can see that resistivity values vary from $9 \mathrm{Ohm}-\mathrm{m}$ to $200 \mathrm{Ohm}-\mathrm{m}$. The geological units expected at the area are the Upper and Middle layer as they are described in previous session. High resistivity values correspond to marly limestones and white marls. Low resistivity values correspond to clay or to water filled zones of marly limestone.

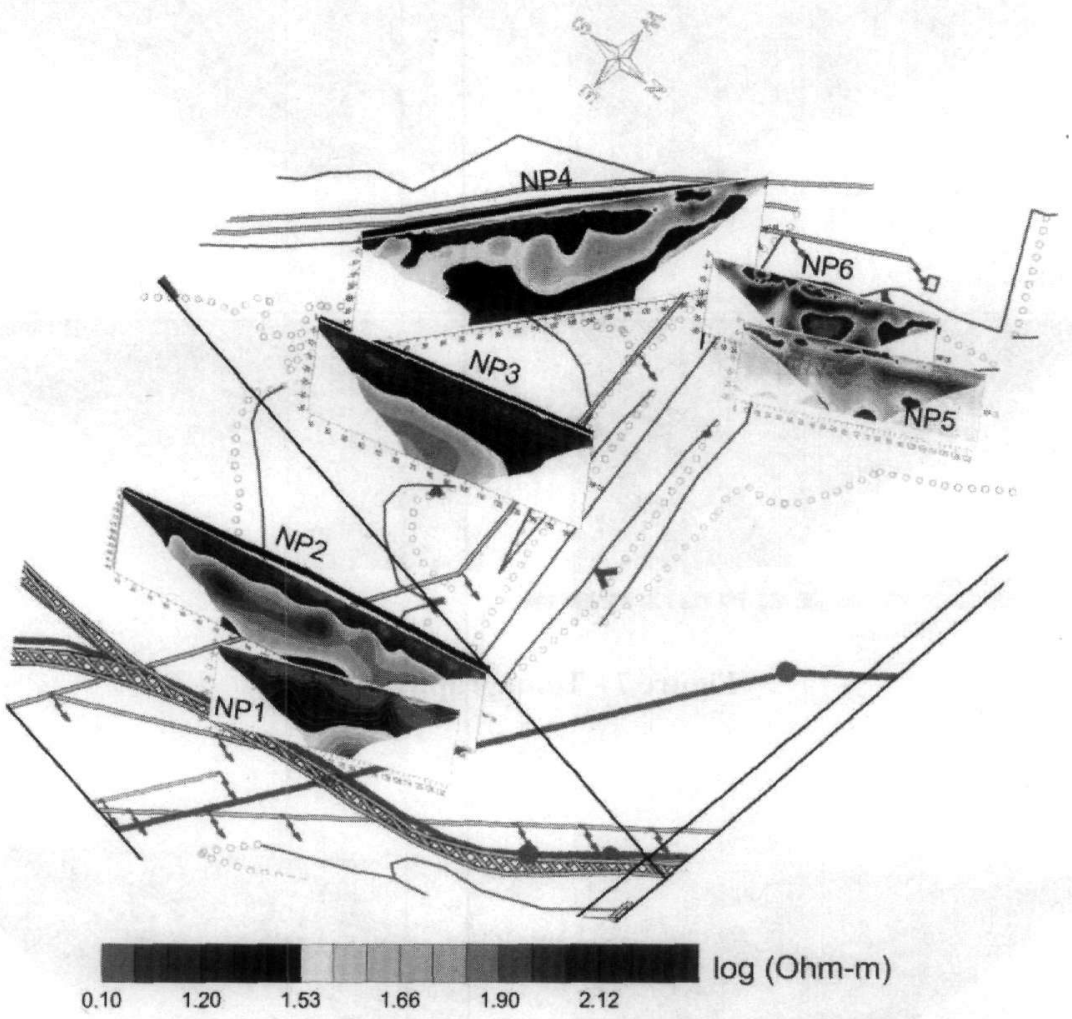

Figure 11 - Combined presentation of ERTS from NP1 to NP6

Geological interpretation taking into account the resistivity distribution suggests that the formation of marly limestone dominates the cross section. At the eastern (right) part of the tomography at the depth of 25 meters argillaceous formation is tracked down in lateral contact with the limestone at 150 meters of the tomography.

The main interest of the tomography is focused in the two conductive zones located at the 70nth and 110 nth meter that are buried at the depth of 15 and 25 meters respectively. In Fig. 8 the projec- 
tion of the spring Q1 is presented as a cross of the ERT and the imaginable line that connects Q1 and Q1a (distance is $45 \mathrm{~m}$.).

From this picture stands to reason that the position of the spring is directly related with the conductive zone in the 70th $\mathrm{m}$. and on the secondhand by the second one in $110 \mathrm{~m}$.. It is believed that these two conductive zones are in correspondence with a faulting system at the area.

NP6 is the closest tomography to the spring Q1. In Fig. 9 the position of the spring is marked on the $102^{\text {nd }}$ meter. It is interesting that exactly at the same location a vertical body which seems having resistivity higher than the lateral formations is detected.

Combined interpretation of both NP6 and NP8 tomographies suggests the crossover of two faults as the favorable path of the underground water flow to the surface.

The first fault is detected from NP5 and NP6 tomographies and it is characterized by an azimuth of ENE-WSW direction. The second one is detected from NP8 tomography and has an azimuth of NW-SE direction. The crossover of these faults is observed to the area where the spring Q1 is located.

\subsection{VLF survey}

VLF data treatment refers to the application of Fraser and Karous-Hjelt filtering. In the figure below we can see the Fraser filtered data (on the top) and Karous-Hjelt filtering in a section of 200 $\mathrm{m}$. and the corresponding tomography at the bottom (NP4).

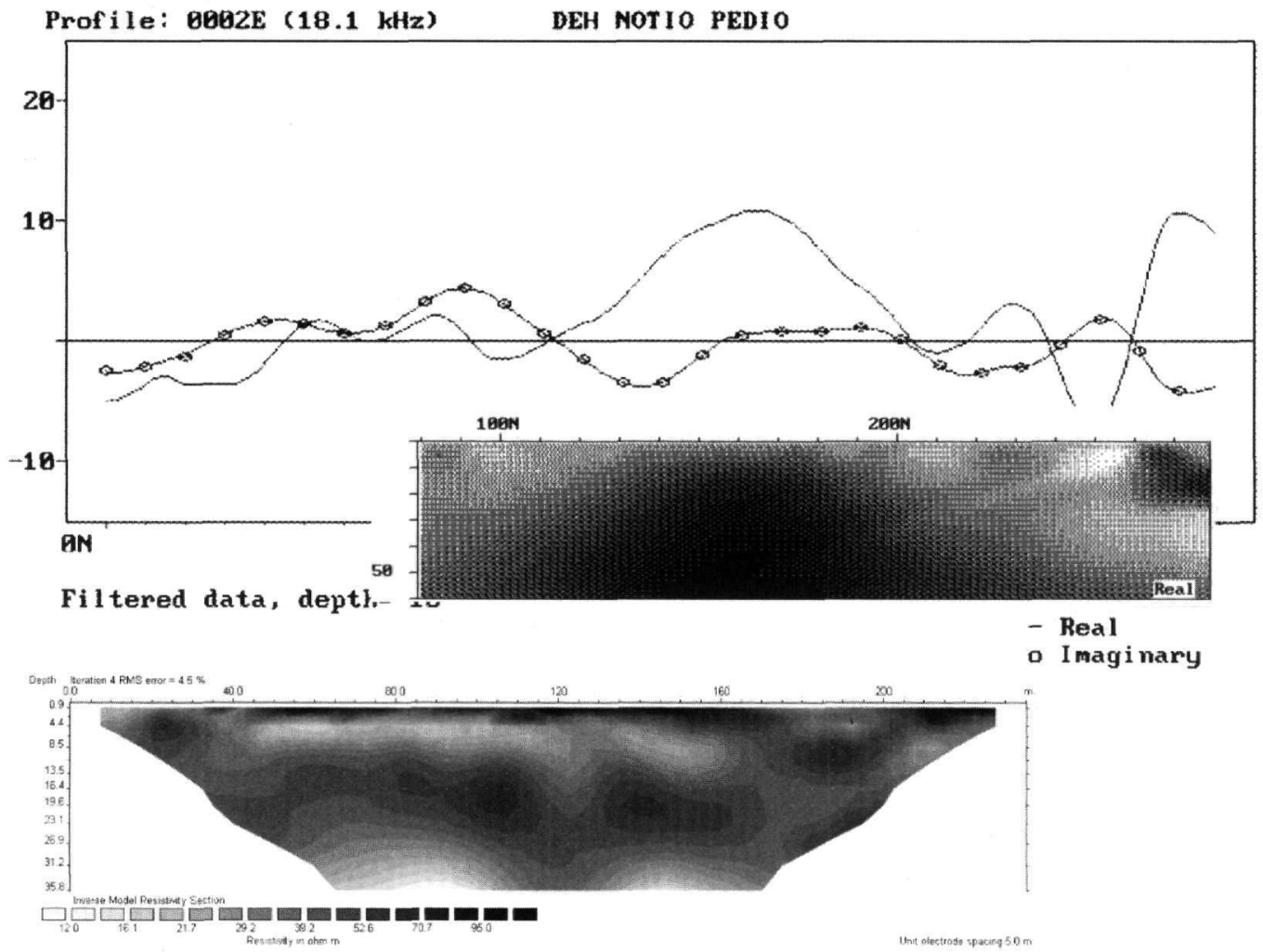

Figure 12 - Presentation of electrical tomography NP4 and VLF profile 2 measured at the same profile 
The conductive zone having center at the 160-170 meters of the VLF profile is in accordance with the discontinuity at 170 meters of the resistivity tomography. This faulting zone is related with Q1A spring.

In the next figure the conductive zones detected from VLF survey are mapped.

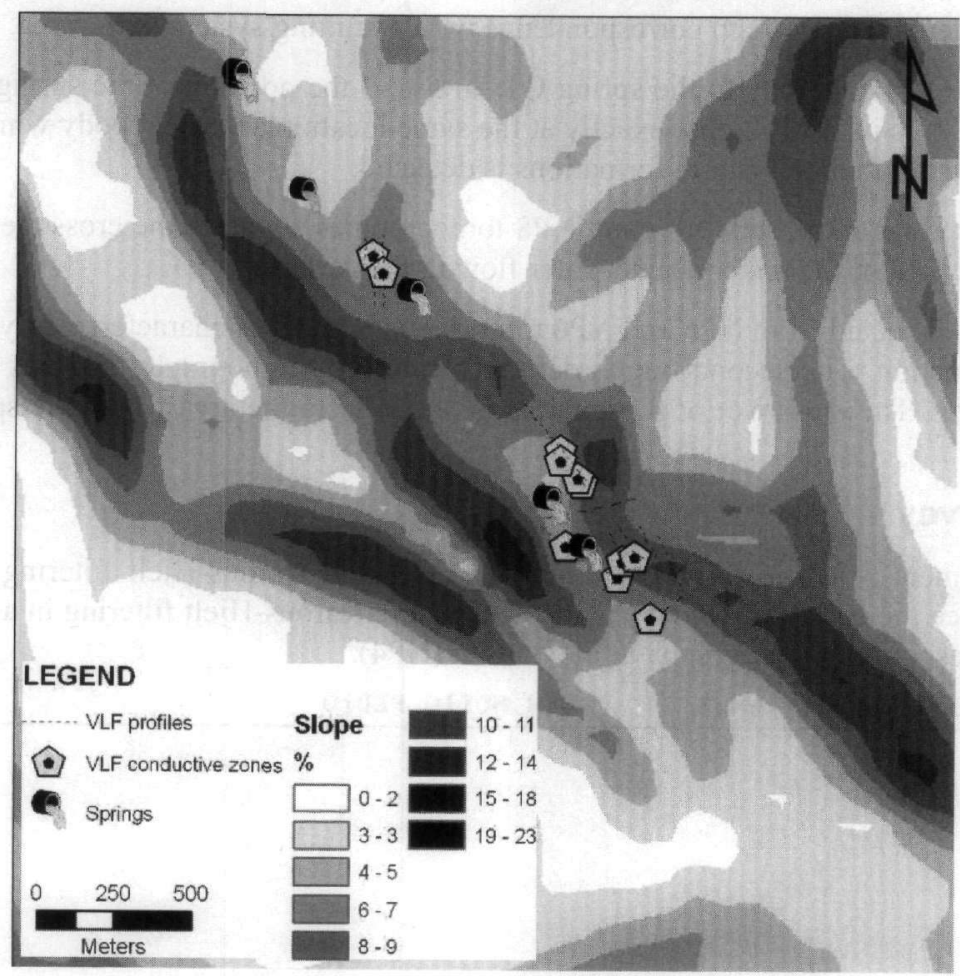

Figure 12 - Conductive zones detected from VLF survey

In the figure above the background topographic map shows the slope of the initial relief of the area. Assuming that the slope of the relief could be an indication of probable faulting structures we can see that VLF conductive zones are elongated along the NorthWest-SouthEast zone of high slope.

\section{Conclusions}

The application of electrical tomography and VLF methods to the study of the mechanism of a group of springs is discussed.

Geophysical survey was of very high importance since the present morphological relief does not correspond to the original geological and tectonic structure of the area as a result of the deposition of excavation products.

Results from the interpretation of geophysical data showed the stratigraphy of the area, pointing out that a superficial layer of marly limestone is lied over a clay/marl/lignite formation. Vertical electric soundings conducted at the area between NP4 and NP6, showed that marl has a great thickness (over 180 meters) and it is the major formation that allows the water flow through preferable faulting zones. The major fault that is detected at the area has a direction of approximately $315^{\circ}$ which is in accordance with the slope of the initial relief as it is formed at the area.

Thus, wells that will penetrate the detected zone are proposed in order to pump the major part of the water to both sides of the valley that is planed to be filled. 


\section{Acknowledgments}

We would like to thank the Power Public Corporation S.A which financed the project. Also, we good like to thank the reviewer for his careful reading of the manuscript and the constitutive suggestions he proposed.

\section{References}

Friedel, S., Thielen, A., and Springman, S.M., 2006. Investigation of a slope endangered by rainfall-induced landslides using 3D resistivity tomography and geotechnical testing, Journal of Applied Geophysics, 60, 100-114.

Li, Y., and Oldenburg, D.W., 1992. Approximate inverse mappings in DC resistivity problems, Geophysical Journal International, 109, 343-362.

Roth, M.J.S., Mackey, J.R., Mackey, C., and Nyquist, J.E., 2002. A case study of the reliability of multielectrode earth resistivity testing for geotechnical investigations in karst terrains, Engineering Geology, 65, 225-232

Sultan, S.A, Helal, A., and Santos, F.A.M., 2004. Geoelectrical application for solving geotechnical problems at two localities in Greater Cairo, Egypt, NRIAG Journal of Geophysics, 3(1), 51-64.

Tsourlos, P., 1995. Modeling interpretation and inversion of multielectrode resistivity survey data, Ph.D. Thesis, University of York. 